\title{
High expression of CX3C chemokine receptor 1 (CX3CR1) in human carotid plaques is associated with vulnerability of the lesions
}

\author{
Marta Masztalewicz ${ }^{1}$, Przemysław Nowacki ${ }^{1}$, Łukasz Szydłowski², Maciej Żukowski², Piotr Gutowski ${ }^{3}$ \\ ${ }^{1}$ Department of Neurology, Pomeranian Medical University in Szczecin, ${ }^{2}$ Department of Anaesthesiology, Intensive Care and Acute \\ Poisoning, Pomeranian Medical University in Szczecin, ${ }^{3}$ Department of Vascular Surgery and Angiology, Pomeranian Medical \\ University in Szczecin, Poland
}

\begin{abstract}
Introduction: In data based on ex vivo studies and animal models, fractalkine is considered an important mediator in the development and destabilization of atherosclerotic plaques. We do not know how it is associated with human carotid plaques morphology.

Material and methods: The study included 126 carotid plaques taken from 126 patients who underwent endarterectomy of internal carotid arteries. We assessed the following characteristics: inflammatory infiltration, connective tissue elements, foam cells, lipid core, plaque vascularisation, calcifications, intraplaque haemorrhage, thrombi built into the plaque structure, and mural thrombi. CX3CR1 expression in plaques as a response to fractalkine was assessed.

Results: Compared to those with a low fractalkine receptor expression, plaques with its high expression exhibited more intensive inflammatory infiltrations. They were more likely to contain inflammatory than fibrous components. They were characterized by a large foam cell component and were less calcified. Intraplaque haemorrhages, the large lipid core and mural as well as intraplaque thrombi were more frequent within them.

Conclusions: High expression of the fractalkine receptor within human carotid plaques is associated with morphological parameters of plaque instability. Thus we conclude that fractalkine may be involved in vulnerability of human carotid plaque.
\end{abstract}

Key words: fractalkine receptor, carotid plaques, plaques morphology.

\section{Introduction}

In data based on ex vivo studies and animal models, fractalkine (CX3CL1) is considered an important mediator in the development and destabilization of atherosclerotic plaques. These roles are attributable to its proinflammatory and prothrombotic features [13,23-26].
The biological activities of CX3CL1 are mediated by CX3C chemokine receptor 1 (CX3CR1) which is expressed on monocytes, natural killer cells, $T$ cells, platelets, and vascular smooth muscle cells (VSMCs). The protein facilitates the migration, adhesion, and proliferation of these cell types via CX3CR1. All of these processes are involved in atherogenesis $[2,4,6,11,13,15,23,25]$. 
To date, case studies of patients with carotid atherosclerosis have confirmed an association between fractalkine expression and the development and severity of atherosclerotic changes in carotid arteries. Yadaw et al. observed a significant correlation between common carotid artery intima-media thickness and the CX3CL1 serum level [27]. Stolla et al. found that fractalkine is expressed in early and advanced carotid lesions, and they observed a relationship between elevated soluble CX3CL1 levels and a high degree of carotid stenosis [26]. However, we do not know how fractalkine is associated with human carotid plaques stability from a morphological point of view. It is unclear whether it is involved in the vulnerability of human carotid plaques. By definition, vulnerable plaques are unstable lesions, prone to rupture, and susceptible to thrombosis $[18,20,22]$.

As mentioned above, fractalkine interacts with a single receptor (CX3CR1) [9,11], and their expressions are positively correlated with each other [26]. Considering that fact, we used CX3CR1 expression in carotid plaques as a marker of response to fractalkine. We aimed to answer the question whether it is associated with plaques morphological instability.

\section{Material and methods}

The study included 126 carotid plaques taken from 126 patients (38 females and 88 males, aged between 40 and 92 years) who underwent endarterectomy of internal carotid arteries. Patients after the ischemic stroke or transient ischemic attack (TIA) or with no history of cerebrovascular events were analysed. They suffered from arterial hypertension, type 2 diabetes, dyslipidemia, lower limb obliterative atherosclerosis, and coronary arterial disease. Some patients had multiple conditions.

We excluded individuals after a possible or probable hemodynamic or cardioembolic stroke (coexistence of hemodynamically significant heart failure, atrial fibrillation, sick-sinus syndrome). We also excluded patients with chronic diseases characterized by inflammation and immunological factors (systemic connective tissue diseases, viral hepatitis, cirrhosis, ulcerative colitis, Crohn's disease, multiple sclerosis, Hashimoto's thyroiditis, Graves' disease, proliferative diseases of the hematopoietic system, other cancers). Another exclusion criterion was immunosuppressant drug use (steroids and cytostatics) within 5 years before study enrolment.

The research was approved by the local Bioethical Commission. The study subjects gave informed consent for their participation.

\section{Microscopic carotid plaque evaluation}

Intraoperatively harvested atherosclerotic plaques were fixed in $10 \%$ formalin solution before they were divided into five parts, including the area most affected by the disease. The material was then submerged in paraffin, sliced into $3-\mu \mathrm{m}$-thick fragments, and stained with haematoxylin and eosin (H\&E).

We assessed the following characteristics: inflammatory infiltration, connective tissue elements, foam cells, lipid core, plaque vascularisation, calcifications, intraplaque haemorrhage, thrombi built into the plaque structure, and mural thrombi. We differentiated plaque shoulders, fibrous cap, and central part including the lipid core (Figs. $1 \mathrm{~A}$ and $\mathrm{B}$, magnification 100x).

Several features considered important for plaque stability were taken into consideration. Parameters of instability were: massive inflammatory infiltrations, dominance of inflammation in relation to the plaque connective tissue component, large foam cells component, large lipid core, increased vascularity, intraplaque haemorrhages, intraplaque thrombus, mural thrombus and plaque rupture. Enlarged plaque calcification, chondro-osseus metaplasia as a dominant calcification type were considered as markers of plaque stability $[1,16,21]$.

1. Inflammatory infiltration:

a) the intensity of inflammation in the plaque shoulder and fibrous cap: inflammatory cells were counted in four visual fields at magnification 400x; infiltration was considered massive if we counted more than 100 cells,

b) the relationship of inflammatory cells with connective tissue elements: the visual fields infiltrated by inflammatory cells to the fields with connective tissue dominance (without or with single inflammatory cells) at magnification 200x; A - inflammation dominance, $B$ - connective tissue dominance.

2. Foam cells component, separately in plaque shoulders and plaque fibrous cap: the component was considered significant if foam cells occupied more than one-third of the shoulder/fibrous cap thickness. 

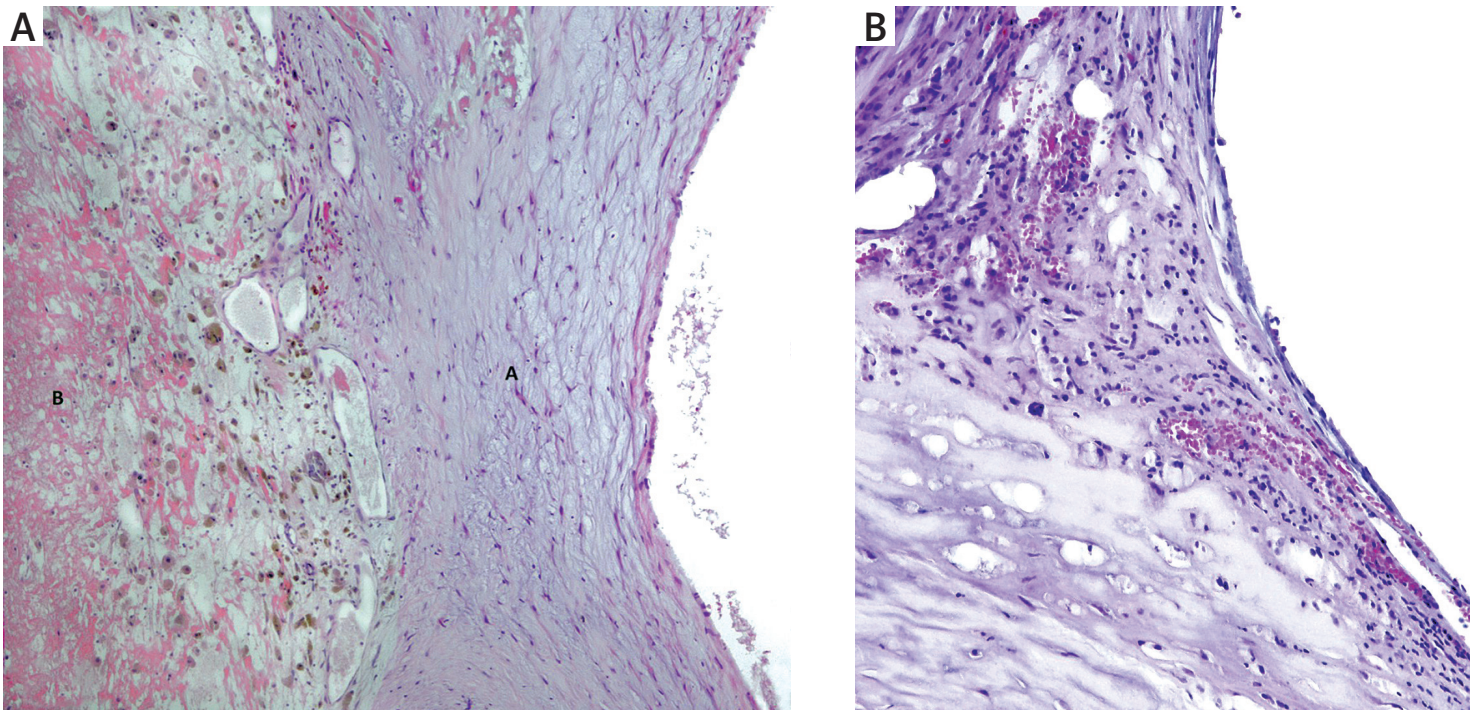

Fig. 1. A) Carotid plaque with visible: A - fibrous cap, B - central part of the lesion; B) carotid plaque - visible shoulder of the lesion.

3. Lipid core (amorphous material containing cholesterol crystals): large if occupied more than half of the plaque thickness.

4. Plaque vascularity: vessel sections counted in four visual fields at magnification 400x: 0, none; I, 1 to 9 sections; II, > 9.

5. Plaque calcification:

a) enlargement of plaque calcification: considered large if calcifications occupied more than half of the plaque surface at magnification 400x,

b) calcifications in shoulders, fibrous cap, and core: considered large if they occupied more than half of shoulder/fibrous cap/core thickness at magnification 200x,

c) dominant calcification type: A - small single or dispersed calcifications, $\mathrm{B}$ - nodules, $\mathrm{C}$ - chondroosseus metaplasia (separately in the fibrous cap, shoulder, and core).

6. Intraplaque haemorrhage (separately in the fibrous cap, shoulder, and core): area of erythrocytes within the plaque causing disorganization of plaque architecture or evident organized haemorrhage with accumulation of hemosiderin-laden macrophages or iron deposition within plaque connective tissue.

7. Intraplaque thrombus: organized collection of fibrin and red blood cells within the plaque.

8. Mural thrombus: organized collection of fibrin and red blood cells in the vessel lumen.

9. Plaque rupture: clear communication between the lipid core and vessel lumen that was not due to surgery.

\section{CX3CR1 expression in human carotid plaques}

Among 5 fragments of each carotid plaque, one fragment - the most affected by the disease was taken for analysis of CX3CR1 expression. There were 126 specimens examined altogether. We analysed 3- $\mu \mathrm{m}$-thick fragments from plaque hot spots labelled with human anti-CX3CR1 antibodies (Novus Biologicals, $1: 200$ ). The plaques were divided into two groups based on the CX3CR1 expression level. Group I included 54 lesions with single or dispersed CX3CR1-positive cells (plaques with a low CX3CR1 expression and less fractalkine influence), while group II consisted of 72 plaques with clusters of CX3CR1-positive cells (lesions with a high CX3CR1 expression and stronger fractalkine influence) (Fig. 2A and B, magnification 400x). The two groups were compared with reference to the microscopic features mentioned above.

Evaluations of plaque morphology and fractalkine receptor expression were performed at baseline and 3 months later. Both evaluations were performed by one researcher. The second analysis was blinded to the first one. Both were performed without knowledge about clinical data. An intraobserver agreement for plaques morphology parameters ranged between 85 and 98 percent. It was 96.825 percent for assessment of the CX3CR1 expression. 


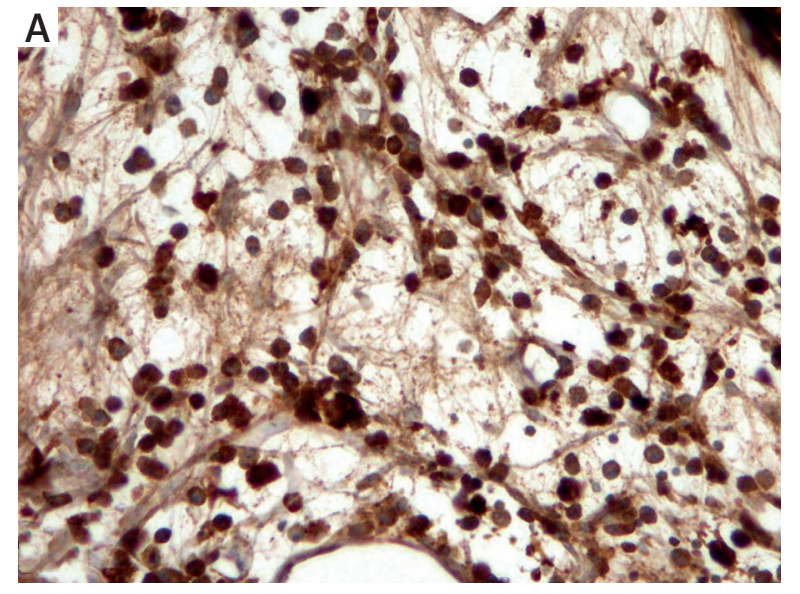

Fig. 2. A) Carotid plaque - high CX3CR1 expression.

\section{Statistical analysis}

Since distributions of most variables were significantly different from normal (Shapiro-Wilk test), the results were presented as a number (percentage) for qualitative variables. Data were compared between groups using the $\chi^{2}$ test for categorical variables. The statistical significance threshold was set at $p<0.05$. Calculations were performed with the use of STATISTICA 10 software.

\section{Results}

\section{CX3CR1 expression and inflammatory infiltrations in carotid plaques}

Compared to those with a low CX3CR1 expression, plaques with its high expression exhibited more intensive inflammatory infiltrations that were predominantly localized in the plaque shoulders (Table I, Fig. 3, magnification 200x). Notably, high CX3CR1expressing plaques were more likely to contain inflammatory than fibrous components (Table I).

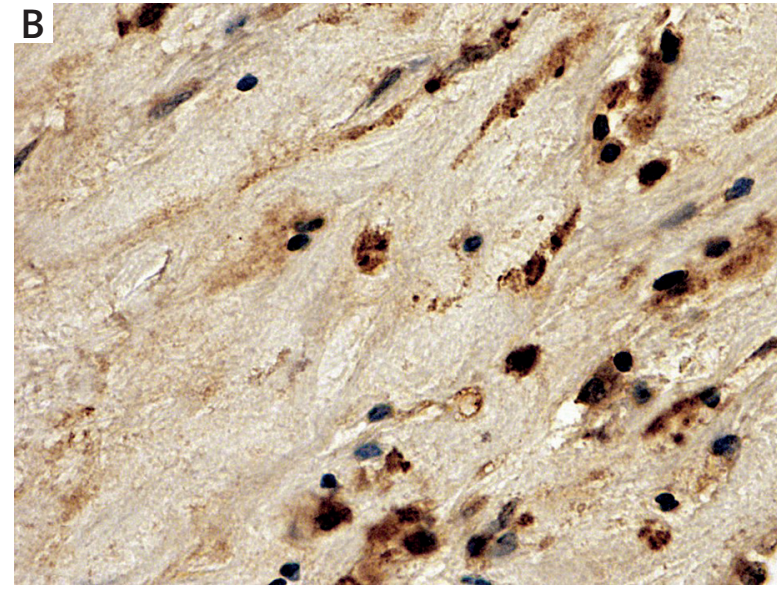

B) Carotid plaque - low CX3CR1 expression.

\section{CX3CR1 expression and foam cell components in carotid plaques}

We found a significant positive association between a carotid plaque CX3CR1 expression and enlargement of foam cells component (Table I, Fig. 4, magnification 200x).

\section{CX3CR1 expression and carotid plaque calcifications}

The plaques with a high CX3CR1 expression were less calcified than plaques with a low expression of the receptor. This was especially clear within the shoulders (Table II, Fig. 5, magnification 200x).

\section{CX3CR1 expression and carotid plaque vascularisation}

We did not find a significant difference in plaque vascularisation between the two groups. High CX3CR1 expression significantly correlated with intraplaque haemorrhages in the plaque fibrous cap, while the

Table I. CX3CR1 expression and cellular component of carotid plaques

\begin{tabular}{|c|c|c|c|}
\hline & $\begin{array}{l}\text { Low CX3CR1 expression, } \\
\qquad n=54\end{array}$ & $\begin{array}{l}\text { High CX3CR1 expression, } \\
\qquad n=72\end{array}$ & $p$ \\
\hline Massive inflammatory infiltration in the fibrous cap & $93.5 \%\left(46^{\star}\right)$ & $86.4 \%\left(66^{\star}\right)$ & 0.8617 \\
\hline Massive inflammatory infiltration in the shoulder & $25 \%\left(48^{*}\right)$ & $47.06 \%\left(68^{\star}\right)$ & 0.0591 \\
\hline \multirow{2}{*}{$\begin{array}{l}\text { The dominance of inflammation in the fibrous cap } \\
\text { in the shoulder }\end{array}$} & $14.89 \%\left(47^{*}\right)$ & $39.71 \%\left(68^{*}\right)$ & 0.0122 \\
\hline & $33.33 \%\left(45^{\star}\right)$ & $49.27 \%\left(69^{*}\right)$ & 0.0421 \\
\hline \multirow{2}{*}{$\begin{array}{l}\text { Significant foam cells component in the fibrous cap } \\
\text { in the shoulder }\end{array}$} & $8.16 \%\left(49^{\star}\right)$ & $22.06 \%\left(68^{\star}\right)$ & 0.0129 \\
\hline & $24.49 \%\left(49^{\star}\right)$ & $47.06 \%\left(68^{\star}\right)$ & 0.0373 \\
\hline
\end{tabular}

*Number of cases with available assessment of particular morphological features 


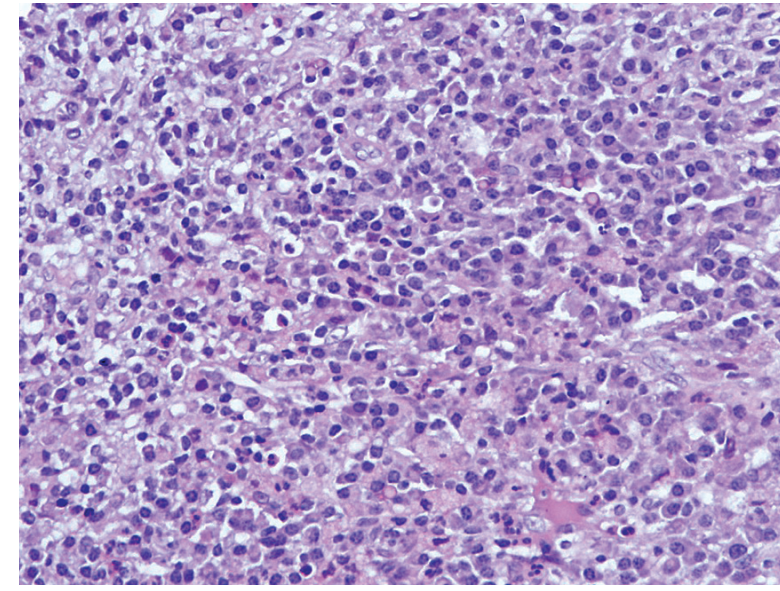

Fig. 3. Visible inflammatory infiltration in the carotid plaque.

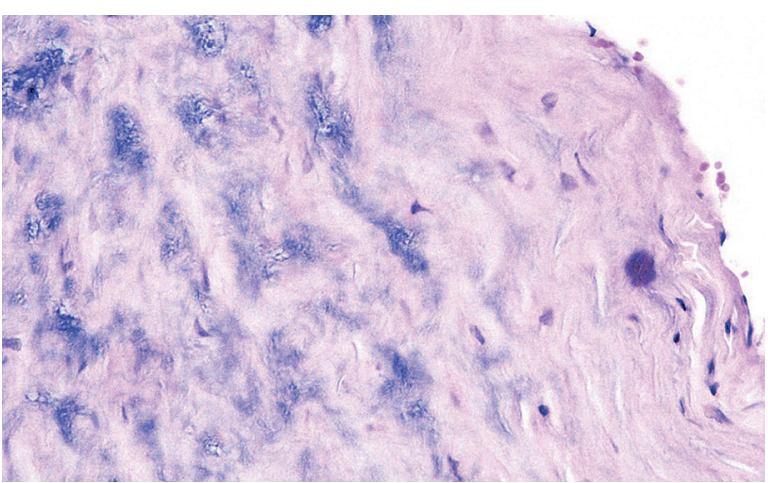

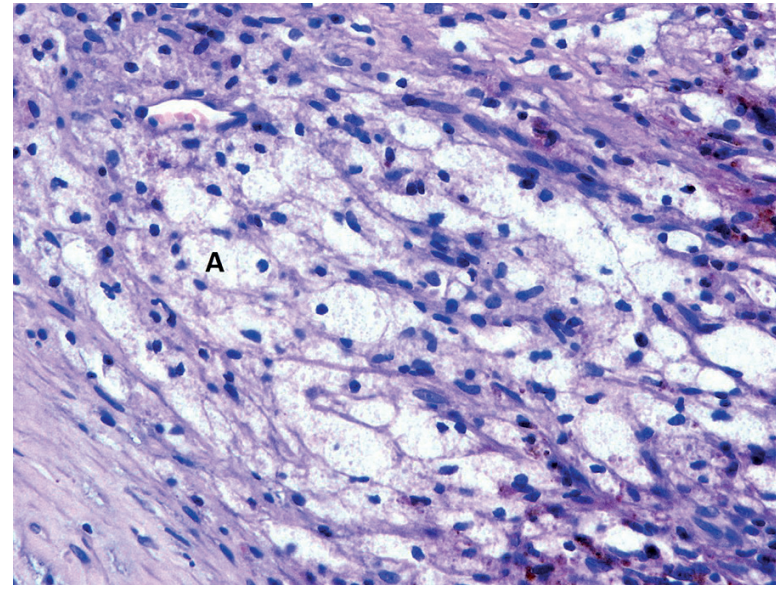

Fig. 4. Visible foam cells component in the carotid plaque. A - foam cell.

trend was toward significance in the shoulder (Table III, Fig. 6 magnification 200x).

\section{CX3CR1 expression and lipid component in carotid plaques}

The large lipid core was more frequent within the plaques with a high CX3CR1 expression than those with a low receptor expression. However, the difference was not quite significant (Table IV).

Fig. 5. Visible dispersed calcifications.

Table II. CX3CR1 expression and carotid plaque calcifications

\begin{tabular}{|c|c|c|c|}
\hline & $\begin{array}{c}\text { Low CX3CR1 expression, } \\
\qquad n=54\end{array}$ & $\begin{array}{l}\text { High CX3CR1 expression, } \\
\qquad n=72\end{array}$ & $p$ \\
\hline Large calcifications in the plaque & $33.33 \%\left(54^{\star}\right)$ & $19.11 \%\left(68^{*}\right)$ & 0.0621 \\
\hline Large calcification in the shoulder & $55.55 \%\left(54^{\star}\right)$ & $34.72 \%\left(72^{\star}\right)$ & 0.0167 \\
\hline Large calcification in the fibrous cap & $50 \%\left(54^{*}\right)$ & $38.89 \%\left(72^{\star}\right)$ & 0.2133 \\
\hline \multicolumn{4}{|c|}{ Dominant calcifications type in the fibrous cap } \\
\hline A & $62.96 \%\left(54^{\star}\right)$ & $81.94 \%\left(72^{\star}\right)$ & \multirow{3}{*}{0.0460} \\
\hline B & $5.56 \%\left(54^{*}\right)$ & $1.39 \%\left(72^{*}\right)$ & \\
\hline C & $31.48 \%\left(54^{\star}\right)$ & $16.67 \%\left(72^{\star}\right)$ & \\
\hline \multicolumn{4}{|c|}{ Dominant calcifications type in the plaque shoulder } \\
\hline A & $46.3 \%\left(54^{\star}\right)$ & $54.17 \%\left(72^{\star}\right)$ & \multirow{3}{*}{0.4778} \\
\hline B & $7.4 \%\left(54^{\star}\right)$ & $5.55 \%\left(72^{*}\right)$ & \\
\hline C & $46.3 \%\left(54^{\star}\right)$ & $40.28 \%\left(72^{*}\right)$ & \\
\hline \multicolumn{4}{|c|}{ Dominant calcifications type in the central part of the plaque } \\
\hline A & $42 \%\left(50^{\star}\right)$ & $60.56 \%\left(71^{\star}\right)$ & \multirow{3}{*}{0.0587} \\
\hline B & $8 \%\left(50^{\star}\right)$ & $8.45 \%\left(71^{\star}\right)$ & \\
\hline C & $50 \%\left(50^{\star}\right)$ & $30.99 \%\left(71^{\star}\right)$ & \\
\hline
\end{tabular}

*Number of cases with available assessment of particular morphological features

A-Small single or dispersed calcifications, $B$ - nodules, $C$ - chondro-osseus metaplasia 
Table III. CX3CR1 expression and carotid plaque vascularisation

\begin{tabular}{|c|c|c|c|}
\hline & $\begin{array}{l}\text { Low CX3CR1 expression, } \\
\qquad n=54\end{array}$ & $\begin{array}{l}\text { High CX3CR1 expression, } \\
\qquad n=72\end{array}$ & $p$ \\
\hline $\begin{array}{c}\text { Vascularity of the fibrous cap } \\
0 \\
1 \\
\text { II }\end{array}$ & $\begin{array}{c}47.92 \%\left(48^{\star}\right) \\
35.42 \%\left(48^{\star}\right) \\
16.66\left(48^{\star}\right)\end{array}$ & $\begin{array}{l}56.92 \%\left(65^{\star}\right) \\
24.62 \%\left(65^{\star}\right) \\
18.46 \%\left(65^{\star}\right)\end{array}$ & 0.5530 \\
\hline $\begin{array}{c}\text { Vascularity of the plaque shoulder } \\
0 \\
1 \\
\text { II }\end{array}$ & $\begin{array}{l}23.4 \%\left(47^{\star}\right) \\
23.4 \%\left(47^{\star}\right) \\
53.2 \%\left(47^{\star}\right)\end{array}$ & $\begin{array}{l}15.15 \%\left(66^{\star}\right) \\
22.73 \%\left(66^{\star}\right) \\
62.12 \%\left(66^{\star}\right)\end{array}$ & 0.3363 \\
\hline $\begin{array}{c}\text { Vascularity of the plaque central part } \\
0 \\
1 \\
\text { II }\end{array}$ & $\begin{array}{c}23.91 \%\left(46^{\star}\right) \\
17.39 \%\left(46^{\star}\right) \\
58.7 \%\left(46^{\star}\right)\end{array}$ & $\begin{array}{l}27.9 \%\left(61^{\star}\right) \\
21.3 \%\left(61^{\star}\right) \\
50.8 \%\left(61^{*}\right)\end{array}$ & 0.6729 \\
\hline Intraplaque haemorrhage in the fibrous cap & $16.33 \%\left(49^{\star}\right)$ & $32.35 \%\left(68^{*}\right)$ & 0.0459 \\
\hline $\begin{array}{l}\text { Intraplaque haemorrhage in the plaque } \\
\text { shoulder }\end{array}$ & $46.94 \%\left(49^{\star}\right)$ & $63.23 \%\left(68^{*}\right)$ & 0.0813 \\
\hline $\begin{array}{l}\text { Intraplaque haemorrhage in central part of } \\
\text { plaque }\end{array}$ & $50 \%\left(48^{\star}\right)$ & $31,14 \%\left(61^{*}\right)$ & 0.1661 \\
\hline
\end{tabular}

*Number of cases with available assessment of particular morphological features

0 - no vessel sections counted in four visual fields at magnification 400x; I, 1 to 9 vessel sections; II, > 9 vessel sections counted in four visual fields at magnification $400 x$

\section{Relationships between CX3CR1 expression and plaque rupture and mural and intraplaque thrombi}

The percentage of ruptured plaques was significantly lower in group I lesions compared to group II. However, mural thrombi were significantly more frequent in group I plaques (Table IV). Intraplaque thrombi were also more frequent in group I, but this difference was not significant (Table IV).

\section{Discussion}

Our findings demonstrate that fractalkine may influence human carotid plaque morphology. The plaques with a greater CX3CR1 expression (supposed stronger influence of fractalkine) possessed a significantly larger component of inflammatory cells infiltration than lesions with a low CX3CR1 expression. We also observed that plaques in the high CX3CR1 expression group exhibited larger inflamma-

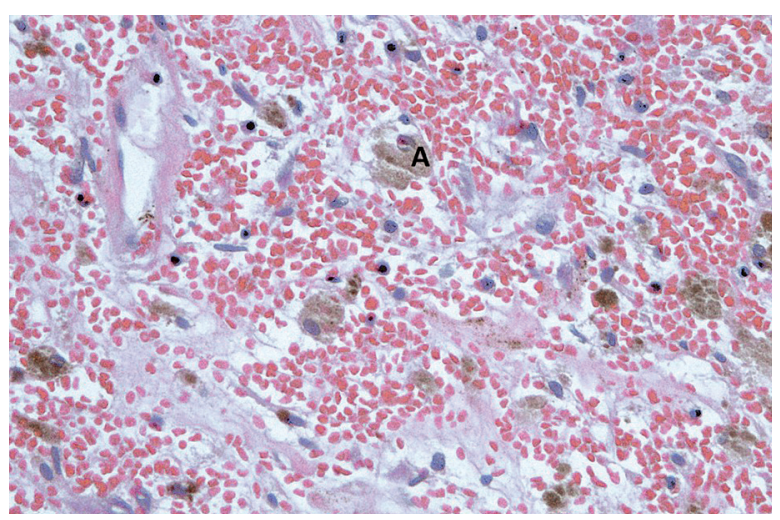

Fig. 6. Visible intraplaque haemorrhage in the carotid plaque. A - hemosiderin-laden macrophage.

tory components compared to fibrous components. Our results are in agreement with limited data from experimental studies of carotid arteries and fractalkine. Cheng et al. assessed apolipoprotein E knockout mice and found that fractalkine stimulated mono-

Table IV. CX3CR1 expression and other features considered important for plaque stability

\begin{tabular}{|c|c|c|c|}
\hline & Low CX3CR1 expression, $n=54$ & High CX3CR1 expression, $n=72$ & $p$ \\
\hline Large lipid core & $54.9 \%\left(51^{\star}\right)$ & $56.34 \%\left(71^{\star}\right)$ & 0.0656 \\
\hline Plaque rupture & $26.53 \%\left(49^{*}\right)$ & $11.76 \%\left(68^{\star}\right)$ & 0.0412 \\
\hline Mural thrombi & $44.23 \%\left(52^{\star}\right)$ & $63.23 \%\left(68^{\star}\right)$ & 0.0381 \\
\hline Intraplaque thrombi & $4.08 \%\left(49^{\star}\right)$ & $15.49 \%\left(71^{\star}\right)$ & 0.1611 \\
\hline
\end{tabular}

*Number of cases with available assessment of particular morphological features 
cyte/macrophage accumulation and reduced carotid plaque collagen content [5]. Our results also suggest that fractalkine promotes inflammation in plaques. The imbalance between inflammatory and reparative mechanisms within atherosclerotic plaques is considered to promote plaque destabilization and is a feature of vulnerable plaques [14].

We observed that plaques with a high CX3CR1 expression had significantly more foam cells and were more likely to have a large lipid-necrotic core compared to plaques with a low CX3CR1 expression. Based on this, we hypothesize that fractalkine promotes foam cells accumulation and lipid-necrotic core formation similarly to what has been reported in animal models [5]. A close connection between high CX3CR1 levels and large lipid core, as well as active inflammation and destruction of plaque fibrous elements, are considered major criteria for plaque vulnerability, emphasizing the role of fractalkine in carotid lesion destabilization $[1,18]$.

Calcifications should be also taken into consideration during carotid plaque morphological analysis. Generally, non-calcified/low calcified plaques are treated as high risk lesions because they are associated more with cerebrovascular events than calcified lesions [18-20,22]. We also observed (data not shown) that less calcified plaques were significantly more frequent symptomatic than lesions with enlarged calcification.

The results mentioned above have shown that plaques with a high expression of CX3CR1 (under stronger influence of fractalkine) were significantly less calcified than plaques of the other group. They were more likely to contain small single or dispersed deposits. Conversely, we observed evidence of chondro-osseus metaplasia in group II plaques. These seem to be a further confirmation for association of fractalkine with human carotid plaques vulnerability $[7,10]$.

High CX3CR1 expression was significantly associated with the presence of intraplaque haemorrhages, another feature of plaque instability. Based on the literature, fractalkine is involved in the neovascularisation of atherosclerotic plaques, and these immature vessels may be a source of intraplaque haemorrhage $[8,12]$.

We observed a significant association between a high CX3CR1 expression and mural thrombi; however, these characteristics were not related to plaque rupture frequency (group I) [3]. Our data suggest that fractalkine may promote mural thrombus formation without plaque rupture. Experimental data suggest that fractalkine activates platelets to stimulate their adhesion and aggregation [24]. The interaction between fractalkine receptors (CX3CR1) on platelets with membranous fractalkine on endothelial cells is responsible for platelet adhesion to the endothelium [17,24].

We assessed the fractalkine influence parameter within the plaques and we observed that it is associated with plaques instability. To answer whether fractalkine could be used as a marker of unstable carotid plaques, additional analysis of plaque morphology with a fractalkine blood level should be performed.

\section{Conclusions}

High expression of the fractalkine receptor within human carotid plaques is associated with morphological parameters of plaque instability. Thus we conclude that fractalkine may be involved in vulnerability of the human carotid plaque.

\section{Disclosure}

Authors report no conflict of interest.

\section{References}

1. Alsheikh-Ali AA, Kitsios GD, Balk EM, Lau J, Ip S. The vulnerable atherosclerotic plaque: scope of the literature. Ann Intern Med 2010; 153: 387-395.

2. Apostolakis S, Spandidos D. Chemokines and atherosclerosis: focus on the CX3CL1/CX3CR1 pathway. Acta Pharm Sin 2013; 34: 1251-1256

3. Badimon L, Vilahur G. Thrombosis formation on atherosclerotic lesions and plaque rupture. J Intern Med 2014; 276: 618-632.

4. Bazan JF, Bacon KB, Hardiman G, Wang W, Soo K, Rossi D, Greaves DR, Zlotnik A, Shall TJ. A new class of membrane-bound chemokine with a CX3C motif. Nature 1997; 385: 640-644.

5. Cheng C, Tempel D, van Haperen R, de Boer HC, Segers D, Huisman M, Zonneveld AJ, Leenen PJM, Steen A, Serruys PW, de Crom R, Krams R. Shear stress-induced changes in atherosclerotic plaque composition are modulated by chemokines. J Clin Invest 2007; 117: 616-626.

6. Cybulsky MI, Hegele RA. The fractalkine receptor CX3CR1 is a key mediator of atherogenesis. J Clin Invest 2003; 111: 1118-1120.

7. Davaine J-M, Quillard T, Brion R, Lapérine O, Guyomarch B, Merlini T, Chatelais M, Guilbaud F, Brennan MA, Charrier C, Heymann D, Gouëffic Y, Heymann MF. Osteoprotegerin, pericytes and bone-like vascular calcification are associated with carotid plaque stability. PLoS One 2014; 9: e107642.

8. Doyle B, Caplice N Plaque neovascularization and antiangiogenic therapy for atherosclerosis. J Am Coll Cardiol 2007; 49: 2073-2080.

9. Haskell CA, Cleary MD, Charo IF. Unique role of the chemokine domain of fractalkine in cell cupture. Kinetics of receptor dis- 
sociation correlate with cell adhesion. J Biol Chem 2000; 275: 34183-34189.

10. Hunt J, Fairman R, Mitchell ME, Carpenter JP, Golden M, Khalapyan T, Wolfe M, Neschis D, Milner R, Scoll B, Cusack A, Mohler ER 3rd. Bone formation in carotid plaques. A clinicopathological study. Stroke 2002; 33: 1214-1219.

11. Imai T, Hieshima K, Haskell C, Baba M, Nagira M, Nishimura M, Kakizaki M, Takagi S, Nomiyama H, Shall TJ, Yoshie O. Identification and molecular characterization of fractalkine receptor CX3CR1, which mediates both leukocyte migration and adhesion. Cell 1997; 91: 521-530.

12. Kumar A-S, Martin K, Turner EC, Buneker ChK, Dorgham K, Deterre Ph, Caplice NM. Role of CX3CR1 receptor in monocyte/ macrophage driven neovascularization. PLoS One 2013; 8 : e57230.

13. Lesnik P, Haskell CA, Charo IF. Decreased atherosclerosis in CX3CR-/-mice reveals a role for fractalkine in atherogenesis. J Clin Invest 2003; 111: 333-340.

14. Libby P, Tabas I, Fredman G, Fisher E. Inflammation and its resolution as determinants of acute coronary syndromes. Circ Res 2014; 114: 1867-1879.

15. Lucas AD, Bursill C, Guzik TJ, Sadowski J, Channon KM, Greaves DR. Smooth muscle cells in human atherosclerotic plaques express the fractalkine receptor CX3CR1 and undergo chemotaxis to the CX3C chemokine fractalkine (CX3CL1). Circulation 2003, 108: 2498-2504.

16. Masztalewicz M, Nowacki P, Bajer-Czajkowska A, Kotfis K, Biernawska J, Safranow K, Żukowski M, Gutowski P. Circulated CD4+CD28- lymphocytes rate and their cytotoxicity and morphological parameters of internal carotid artery atheromatous plaques in patients with atherosclerosis-related ischemic stroke. Folia Neuropathol 2013; 51: 250-260.

17. Meyer dos Santos S, Klinkhardt U, Scholich K, Nelson K, Monsefi N, Deckmyn H, Kuczka K, Zorn A, Harder S. The CX3C chemokine fractalkine mediates platelet adhesion via the von Willebrand receptor glycoprotein Ib. Blood 2011; 117: 4999-5008.

18. Naim C, Douziech M, Therasse E, Robillard P, Giroux MF, Arsenault F, Cloutier G, Soulez G. Vulnerable atherosclerotic carotid plaque evaluation by ultrasound, computed tomography angiography and magnetic resonance imaging: an overview. Can Assoc Radiol J 2014; 65: 275-286.

19. Nandalur KR, Baskurt E, Hagspiel KD, Philips CD, Kramer ChM. Calcified carotid atherosclerotic plaque is associated less with ischemic symptoms than is noncalcified plaque on MDCT. AJR AM J Roentgenol 2005; 184: 295-298.

20. Nighoghossian N, Derex L, Douek P. The vulnerable carotid artery plaque: current imaging methods and new perspectives. Stroke 2005; 36: 2763-2772.

21. Redgrave JN, Lovett JK, Gallagher PJ, Rothwell PM. Histological assessment of 526 symptomatic carotid plaques in relation to the nature and timing of ischemic symptoms. Circulation 2006; 113: 2320-2328.

22. Saba L, Anzidei M, Marincola BC, Piga M, Raz E, Bassareo PP, Napoli A, Manneli L, Catalano C, Wintermark M. Imaging of the carotid artery vulnerable plaque. Cardiovasc Intervent Radiol 2014; 37: 572-585.
23. Saederup N, Chan L, Lira SA, Charo IF. Fractalkine deficiency markedly reduces macrophage accumulation and atherosclerotic lesion formation in CCR2-/- mice: evidence for independent chemokine functions in atherogenesis. Circulation 2008; 117: 1642-1648.

24. Schäfer A, Schultz C, Eigenthaler M, Fraccarollo D, Kobsar A, Gawaz M, Ertl G, Walter U, Bauersachs J. Novel role of the membrane-bound chemokine fractalkine in platelet activation and adhesion. Blood 2004; 103: 407-412.

25. Schultz C, Schäfer A, Stolla M, Kerstan S, Lorenz M, von Brühl ML, Schiemann M, Bauersachs J, Gloe T, Busch DH, Gawaz N, Massberg S. Chemokine fractalkine mediates leukocyte recruitment to inflammatory endothelial cells in flowing whole blood: a critical role for P-selectin expressed on activated platelets. Circulation 2007; 116: 764-773.

26. Stolla M, Pelisek J, von Brühl ML, Schäfer A, Barocke V, Heider P, Schiemann M, Bauersachs J, Gloe T, Busch DH, Gawaz M, Massberg S. Fractalkine is expressed in early and advanced atherosclerotic lesions and supports monocytes recruitment via CX3CR1. PLoS One 2012; 7: e43572.

27. Yadav AK, Lal A, Jha V. Association of circulating fractalkine (CX3CL1) and CX3CR1(+)CD4(+) T cells with common carotid artery intima-media thickness in patients with chronic kidney disease. J Atheroscler Thromb 2011; 18: 958-965. 